\title{
DOS PROCESOS SINGULARES: LOS DE FRAY LUIS DE LEÓN Y ANTONIO ENRÍQUEZ GÓMEZ*
}

El hecho de sacar del común estos, dos procesos singulares, obedece a razones prácticas a la vez que a ciertas conjeturas teóricas. Por tratarse de estereotipos, la historia ha sido aquí terriblemente simplificada y, por lo tanto, aquí a lo menos, hay que compilarla para aclararla. El nudo de la complicación es el carácter judio o judaico de ambos procesos.

La razón práctica es la importancia casi legendaria de las dos causas: la de fray Luis "por ser vos quien sóis", y la de Enríquez, por lo novelesco de su asunto. ¿En qué otro proceso el reo ve desde las tablas - como quien dice - quemar su persona en efigie? En ambos casos era difícil, por no decir imposible, resumir sin hacer injusticia a la historia y al lector, que podría creer que estos dos procesos son lugares comunes. Ni lo son, ni merecen estar juntos, sino como polos opuestos o, a lo menos, como momentos muy distintos de un mismo problema: el del judaísmo moderno en sus relaciones con la Inquisición española.

El proceso de fray Luis es singular por la amistad de éste con los inquisidores, especialmente con los Inquisidores Generales Quiroga y Portocarrero; el de Antonio Enríquez, por todo lo contrario. Las acusaciones contra fray Luis venían de fuera; las de Enríquez de muy adentro. Ambos son escritores de origen judeoconverso. Pero a qué distancias. Les une, sin embargo, ese lema elegido por fray Luis a la salida de la cárcel: ab ipso ferro. La adversidad les inspiró, aunque también de formas muy distintas: la Inquisición hizo de Enríquez un judío exiliado de España y un panfletario utópico; fray Luis es un cristiano exiliado de la tierra y un excelso poeta platónico.

* El presente ensayo forma parte de una obra más extensa de carácter general, Literatura e Inquisición en España, publicada por la editorial Taurus, Madrid, 1980. A causa de las dificultades que hubo en el curso de la publicación de este volumen, el artículo aparece con un atraso que al iniciar la edición no podíamos prever (N. de la R.). 
Fray Luis de León (1527-1591)

El proceso o procesos de fray Luis, pues son dos, han sido estudiados repetidas veces y lo siguen siendo aún. Menéndez Pelayo en los Heterodoxos, con su característica exageración dice que: "'Del proceso de Fr. Luis de León fuera temeridad decir nada, después del magistral y definitivo Ensayo histórico del mejicano don Alejandro Arango y Escandón, modelo de sobriedad, templanza, buen juicio y buen estilo". Después se han publicado los estudios clásicos de Reusch (1873), Getino (1907), Bell (1914) y últimamente la tesis doctoral de William Afton Lusk, Fray Luis de León y la Inquisición, defendida en la universidad de Maryland, en 1961.

A pesar de todos esos estudios y de diversas biografías, la más reciente de las cuales es la de Manuel Durán, quedan notables tareas por hacer en este notable proceso de la Inquisición, quizás el más conocido de todos ellos. La primera es la fijación de los textos de ambos procesos, particularmente del primero y principal, nunca publicado íntegramente, aunque así se acepta incluso por los investigadores más exigentes.

Es opinión común creer que el primer proceso (1572-1576), se encuentra íntegro en la Colección de documentos inéditos para la hist. de España, en los volúmenes X y XI (Madrid, 1847); y "extractado", en la Biblioteca de Autores Españoles, vol. 37, a continuación de la biografía de Mayáns. Pero basta leer la transcripción de DECOIN, aun sin cotejarla con el manuscrito, para advertir los pasajes omitidos, defecto que los editores no ocultan. En el tomo XI, p. 118, anotan: "Fray Luis de León continúa citando muchos pasajes de autores católicos que suprimimos [subrayado mío] en gracia de los lectores." Y en la página 131 del mismo volumen: "Sigue un escrito del doctor Ortiz de Funes como abogado de Fray Luis de León, lleno de citas de jurisconsultos, y de lectura empalagosa e indigesta, que omitimos [subrayado añadido] por no ofrecer novedad ni aumentar el interés de la defensa". Y, sin embargo, los eruditos siguen tan contentos y satisfechos.

Sea, pues, la primera consideración sobre el más famoso de los procesos de escritores, afirmar que el público no posee un texto completo y fidedigno debidamente editado y anotado, como el que poseemos, por ejemplo, del de María de Cazalla (Ortega Costa) o del de Blanquina March, madre de Luis Vives, obra de

${ }^{1}$ Heterodoxos, t. 4, p. 419. 
Palacios. Esto en cuanto al primero y principal proceso. El texto del segundo fue editado en un folleto de cincuenta y cuatro páginas (diecisiete de introducción y treinta y siete de texto), en Madrid, en 1896. Desconozco el paradero del original que en esas fechas estaba en manos particulares ${ }^{2}$.

La parte meramente narrativa del proceso es archiconocida, sobre todo el colofón de "como decíamos ayer..." que si fue dicho, se dijo en latín, la lengua de la clase, a no ser que fray Luis se saltase este precepto académico, lo cual no tendría nada de extraño en un hombre de su calidad y temperamento. Lo más probable es que nunca se dijese, pues fray Luis no volvió a su cátedra, sino a una nueva. El testimonio, además, es tardío y de un extranjero. De haberse pronunciado esas memorables palabras en una ocasión solemne como fue la de su vuelta a Salamanca (de esto sí hay constancia documental), alguien más las habría recordado y citado. De todas formas, la legendaria frase en latín, dicebamus hesterna die, está en perfecta consonancia con el motto elegido por fray Luis, para sus obras, precisamente al salir de la cárcel, y en ofensa de algunos inquisidores menores: $a b$ ipso ferro.

El significado concreto de esta segunda leyenda y la reacción inquisitorial son inequívocos, y sintetizan con precisión el carácter de fray Luis y quizás la totalidad de los resultados entre Literatura e Inquisición en España. Sobre su sentido no hay duda; queda tersamente expresado en la oda IX, a Felipe Ruiz:

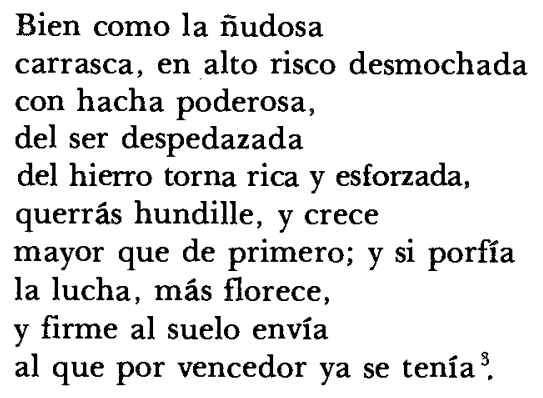

$\mathrm{Y}$ por si todo esto no fuese suficientemente claro, prosigue en la estrofa siguiente: "Exento a todo cuanto / presume la fortuna, sosegado / está y libre de espanto / ante el tirano airado, / de

${ }^{2}$ Segundo Proceso instruido por la Inquisición de Valladolid contra fray Luis de León, con prólogo y notas de Francisco García, Agustino, Madrid, Imprenta de D. Luis Aguado, 1896, 54 pp.

${ }^{3}$ Obras completas castellanas, prólogo y notas de Félix García, $3^{\mathrm{a}}$ ed., Madrid, 1959, pp. 1445-1446; citado en adelante, Obras. 
hierro, de crudeza y fuego armado". En el comentario o Exposición del libro de Job, "de quien parece haber hurtado Horacio aquesta comparación", vuelve fray Luis a esta estrofa que explica ortodoxamente y coloca en la empresa o emblema al frente de todas sus publicaciones a partir de la primera edición en latín de los Cantares (1580) y La perfecta casada, 1583, su primera publicación en castellano ${ }^{4}$.

Los inquisidores de Valladolid tenían razón al considerar el emblema un desacato al Santo Oficio, como también la tenían en su causa contra el ilustre escritor, a quien sólo salva la amistad con los inquisidores Quiroga y Portocarrero. Fray Luis sabía perfectamente que era un serio delito traducir una obra de la Sagrada Escritura al castellano, comentarla en castellano y distribuirla manuscrita. Aunque fuera para una sola persona, la culpa era clara, como claras eran las prohibiciones de los Índices de 1551 y 1559 .

En el primero, la primera obra de la lista de "Libros reprobados en lengua castellana", es la "Biblia en romance castellano o en otra cualquier vulgar lengua". En el segundo, se especifica aún más, prohibiendo en la forma terminante que sólo Valdés sabía usar: "Todos y qualesquier Sermones, Cartas, Tratados, Oraciones, o otra cualquier escritura escripta de mano, que hable o tracte de la sagrada escriptura"5. Es increíble que con estas prohibiciones y las cenizas aún calientes de los autos de fe de Valladolid y Sevilla, fray Luis se ponga a traducir nada menos que el Cantar de los cantares, libro especialmente problemático incluso en épocas menos peligrosas.

A esto hay que añadir varios agravantes. Fray Luis, que insiste en el carácter privado de su traducción, había pensado incluso en publicarla. Con la "Declaración de los cantares", hay una carta original del comisario de la Inquisición en Salamanca, Francisco Sancho, fechada en Madrid, el 16 de julio de 1571, indicándole a fray Luis que no publique esta obra en castellano por estar especialmente prohibida, incluso entre los judíos y en un momento - sigue el comisario - en el que incluso el Catecismo y las Horas en romance están vedadas. "Y ansi —concluye- 6 ternía por más acertado que V. P., como dice en su carta, escribiese la dicha obra en latín, y la perfeccionase en lo que le parestas.

${ }^{4}$ Véanse los distintos facsimiles de las diversas portadas en Obras comple-

${ }^{5}$ Indice de Valdés, 1559, p. 64 (subrayado añadido).

${ }^{6}$ CODOIN, t. 10 , p. 469. 
ciese convenir para sabios y doctos, y tener por mejor contentar a los tales, que no a la turba multa".

Fray Luis no sólo no ha hecho caso al comisario Sancho, sino que al traducir el Cantar ha usado el lenguaje más llano, el que le enseñaron sus amas, y se ha limitado al sentido literal, postergando los tradicionales sentidos espirituales, prefiriendo el texto hebrero al de la vulgata latina y los comentarios rabínicos a los de los santos padres. El resultado final de toda esta suerte de reduccionismos profanos, es una obra no sagrada, sino un poema erótico: carmen amatorium.

Las explicaciones y defensas de fray Luis no satisfacen a los inquisidores de Valladolid, y así votan, como era de costumbre, el 28 de septiembre de 1576, "que el dicho fray Luis de León sea puesto a quistion de tormento"7. Pero el documento a continuación no es el acta de tormento, como en otros procesos, sino la "Sentencia dada por el Consejo de la Suprema en el proceso de fray Luis de León, en 7 de diciembre de 1576". Para administrar el tormento, los inquisidores de distrito necesitaban en este caso el permiso de la Suprema, y la sentencia es la negación de ese permiso. Los señores del Consejo, a cuya cabeza está el Inquisidor General Quiroga, "Mandaron que el dicho fray Luis de León sea absuelto de la instancia deste juicio, y en la sala de la audiencia sea reprendido y advertido. . y que se recoja el cuaderno de los Cantares traducido en romance y ordenado por el dicho fray Luis de León" ".

Según una relación anónima, "año de 76, martes 23 de diciembre, día de San Dámaso, dieron por libre a fr. Luis sin pena”. Según la terminología penitenciaria, había pasado en la cárcel (la cárcel por la que acababa de pasar Carranza y en la que había muerto de lepra Gudiel) cuatro años, ocho meses y veintiséis días: "Jueves a las seis de la tarde veinte y siete de marzo de mil quinientos y setenta y dos años, trajo preso Francisco de Almansa, familiar, a fray Luis de León, contenido en este mandamiento atrás" ".

Aunque "el cuaderno de los Cantares traducido al romance", no es la pieza única del proceso, ciertamente es central en él, sobre todo desde el punto de vista de este estudio. Guillén, que lo ha editado modernamente, lo considera "el mejor Cantar de

${ }^{7}$ CODOIN, t. 11, p. 352.

${ }^{8}$ CODOIN, t. 11, p. 353 (subrayado añadido).

${ }^{9}$ CODOIN, t. 10 , p. 176 . La relación de la llegada a Salamanca en Gallardo, Ensayo, lib. 4, col. 1328; Aubrey Bell, Luis de León, Oxford, 1925, p. 162. 
Cantares castellano". Y Francisco García Lorca, tras un esmerado estudio, cree que San Juan de la Cruz ha sido profundamente influido por su lectura ${ }^{10}$.

A esto hay que añadir que la obra de fray Luis dependía a su vez de la de Arias Montano, a quien le unía una extraña amistad, quizás desde sus años en Alcalá (1556-1557), y un maestro común, Cipriano de Huerga, teólogo bíblico defensor del sentido literal y comentador como fray Luis del Cantar y de Job ${ }^{11}$.

En unas declaraciones o "pedimento" del 9 de noviembre de 1573 , de fray Luis a los Inquisidores, escribe: " $4^{\circ}$ En el cartapacio núm. $4^{\circ}$ no hay cosa mía. Tiene una exposición sobre los Cantares en romance del maestro Benito Arias Montano: prestómela muchos años ha pidiéndosela yo para ver algunos pasos cuando yo escribí sobre ellos, y ansí me aproveché della en algunos lugares. Prestómela con condición que se la pusiese en latín, y yo nunca lo hice por ocupaciones que tuve. Consta ser suya por la letra que es dél, y porque él preguntado, si fuese menester, no lo negarâ"'12.

Arias Montano no fue preguntado, ni fue menester, pues cuatro días después, el 13 de noviembre de 1573, "Fuele mostrado un librito de cuarto de pliego, encuadernado en pergamino blanco, que comienza Esposición sobre el Cantar de los Cantares de Salomón, que parece estaba en los papeles del dicho padre fray Luis, y al cabo de dicho librico, están dos renglones escriptos en hebraico, y dos renglones y medio escriptos en griego, y renglón y medio en arábigo. Y habiéndolo visto, dijo: que el maestro Benito Arias Montano, estremeño o andaluz, habrá diez o once años, poco más o menos, questando este confesante en Salamanca, y pasando por allí dicho Benito Arias, este confesante le pidió que le prestase una exposición en romance sobre los Cantares, la cual este confesante sabía que tenía, porque este confesante escribía a la sazón sobre los mismos Cantares la obra de romance que hizo; y el dicho Benito Arias le respondió que él se los

${ }^{10}$ FRAY LUIS DE LEÓN, Cantar de cantares, ed. y pról. de Jorge Guillén, Cruz del Sur, 1947, p. 143; FRANCISCo GARCÍA LoRCA, De fray Luis a San Juan: la escondida senda, Madrid, 1972.

${ }^{11}$ Según un reciente trabajo de Eugenio Asensio, Cipriano de Huerga estaba ya en Alcalá en 1526, y así no sólo ha podido influir en Arias Montano y fray Luis de León, durante sus respectivos cursos en la universidad, sino en Juan de Valdés. "Exégesis bíblica en España. Encuentro de fray Cipriano de Huerga con Juan de Valdés en Alcalá", en Doce consideraciones sobre el mundo hispanoitaliano en tiempos de Alfonso y juan de Valdés, Roma, Instituto Español de Lengua y Literatura de Roma, 1979.

${ }^{12}$ CODOIN, t. 10 , p. 477 . Subrayado añadido. 
enviaría en yendo a su monasterio de San Marcos de León adonde ios tenía, con condición que tomase este trabajo de volvérselos en latín; y este dijo que lo haría si tuviese desocupación. Y ansí desde algunas semanas se los envió desde San Marcos de León"13. . . "Los dichos Señores Inquisidores dijeron que se dan a calificar los dichos Cantares, para que se entienda si tienen alguna cosa que sea sospechosa en la fee"14.

El Cantar de Montano probablemente no tenía nada contra la fe, pero tenía una larga y sospechosa historia, que nadie ha contado todavía y que no es ésta la ocasión de contar. Baste decir que ya lo tenía traducido en verso castellano en 1554; que había sido arrestado por la Inquisición en Sevilla, el 9 de julio de 1559; y que fray Luis declara ante la Inquisición, diez años antes de su proceso (en 1562) "haber recibido de Montano un libro herético", escrito en italiano, que bien podría ser de Valdés o de su círculo. "Los primeros años después de Alcalá [1553-1556] constituyen un enigma en la vida de Arias Montano, concluye Rekers, de quien son la mayor parte de estos datos ${ }^{15}$.

Los inquisidores, en el contexto del proceso de fray Luis, manifiestan poco interés por la literatura propiamente dicha, como diferente de la teología, que era su menester. Además, el reo estaba todavía lejos de ser considerado una figura literaria. Su primera obra en castellano es La perfecta casada, publicada en 1583, y así los inquisidores, al tropezarse en el legajo número catorce con "cartas misivas y versos en latín y en romance", los tratan como, "cosas que ninguna dellas toca en cosa de teulogía". No así el Cantar y su comentario. Cualquiera que sea su valor poético, la obra es irremediablemente teológica, por más que creamos con Renán que encontrar tal libro en el Canon de las Escrituras Sagradas es como tropezarse con Anacreonte en una colección de teología.

Igualmente teológica es la disposición que se deba hacer de los libros sagrados: si traducirlos al castellano o dejarlos en latín, en griego o en hebrero. Una cosa está clara, y es que en ese momento era peligrosísimo que el pueblo entrase en contacto directo con la Escritura, ya se tratase de enseñarle latín o ponerle el texto en castellano. Fray Luis lo debió oír directamente de boca de su maestro Cano: "es dañoso y peligroso fiar la divina escriptura de mugeres y gente lega, y haze muy poco al caso que la mujer entienda latín, pues es el mesmo peligro"16.

${ }^{13}$ CODOIN, t. 10, p. 491-492. $\quad{ }^{14}$ CODOIN, t. 10, p. 492.

${ }^{15}$ Arias Montano, p. 9.

${ }^{16}$ Censura, de Melchor Cano, al Catecismo, de Carranza. En Fermin CA. 
Fray Luis ha hecho todo lo contrario y contra todo parecer, sin que en el proceso parezca arrepentirse de ello, a juzgar por el tono y contenido de su respuesta a este cargo: "Ansi que a éste [al denunciante o testigo de cargo] el texto le ofende, y yo ya que le puse en romance, no pude excusar de ofendelle, porque no tenía otros vocablos con que romanzar oscula, ubera, amica mea, formosa mea y lo semejante, sino diciendo besos, y pechos, y mi amada, y mi hermosa y otras cosas así, porque no sé otro romance del que me enseñaron mis amas, que es el que ordinariamente hablamos; que a saber el lenguaje secreto y artificio con que este mi testigo y sus consortes suelen declarar sus conceptos, usara de otros vocablos más espirituales"17.

Aparte de la cáustica ironía del final, esta defensa va al corazón del conflicto. El problema del lenguaje es un problema de literatura y de Inquisición, no sólo de cara al escritor, sino de cara sobre todo al lector que es, en último término, el depositario y mensajero del texto. El conflicto del Cantar es por el texto y por el pueblo. ¿Quién lo fija? El escritor no parece darse cuenta de las consecuencias políticas de sus actos poéticos. La lucha por el sentido del Cantar es tan antigua como el Cantar mismo. ¿Cuestión literaria? ¿Cuestión religiosa? Cuestión sociológica; cuestión política. Lucha entre sacerdotes y profetas, poetas y políticos, por la palabra y por el pueblo.

Una última palabra sobre este asunto, antes de pasar a otros aspectos literarios del proceso: la cuestión del carmen amatorium. Al mismo testigo que se ofende de ese romance de amas en un libro sagrado, la declaración de fray Luis, es decir, su comentario, "le parece toda una carta de amores sin ningún espíritu, y indigna de llamarse declaración de la sagrada escritura"18. Recuérdese que la obra, como otras de fray Luis, está hecha específicamente para una mujer y que la primera proposición condenada no sólo en su obra, sino en toda la escuela salmanticense es: $1^{\text {a }}$. Canticum Canticorum est carmen Salomonis ad filiam Pharaonis, et contrarium docere est futile (Primera, el Cantar de los Cantares es un poema de Salomón a la hija del Faraón, y es inútil enseñar lo contrario) ${ }^{19}$.

Los patrocinantes de esta sentencia, ut fertur, son Martín Martínez de Cantalapiedra, Gaspar de Grajal y Luis de León, to-

BAllero, Vida del Illmo. Melchor Cano, Madrid, 1874, Apéndice 58, p. 451 .

${ }^{17}$ CODOIN, t. 10 , pp. 364-365.

${ }^{18}$ CODOIN, t. 10 , p. 362.

19 "Proposiciones entregadas al Consejo de la Suprema por el P. Pedro 
dos defensores del sentido literal, contra el sentido alegórico. Entre ellos circula un proverbio o chiste por el cual llaman "El sabio Alegorim", al que usa de los sentidos o significados alegóricos que los Santos dieron a las Escrituras. Sentido literal y sentido alegórico, en este caso, se resuelven en la lucha por el eros y el ágape. El sentido literal conduce directa y prontamente al problema del amor divino y del amor profano, cuyas relaciones - según Hatzfeld - son las más importantes y las menos estudiadas de toda la literatura occidental. Dejemos, pues, el tema aquí simplemente enunciando: lo característico de fray Luis y su problema era el ser un gran humanista que profesa teología. $\mathrm{Hu}$ manismo y teología no son fáciles de ensamblar sin grandes descoyuntamientos. Ningún grupo ideológico ha tenido más conflictos con la Inquisición que el de los llamados humanistas, biblistas o hebraístas.

\section{OIROS ASPECIOS LIIERARIOS DEL PROCESO}

El Cantar, entre otras razones, llevó a fray Luis a la cárcel; en revancha, la cárcel se convierte para fray Luis en un taller de otros cantares indudablementee más excelsos, aunque solamente se mire su ángulo poético. En otras palabras, atentos a la empresa o emblema, el hierro, al querer hundirla, exalta su poesía; la égloga asciende a otras esferas o desciende al abismo, al tener que replegarse sobre sí misma.

Aunque no es fácil precisar qué poemas fueron escritos en la cárcel y cuáles no, hay un conjunto claramente definible, en el que el pathos de la prisión, real o figurada, es la razón de ser poética. Como curioso contraste, adviértase al mismo tiempo que los poemas, aparte de sus dedicatorias individuales, están dedicados como conjunto al inquisidor Portocarrero, dos veces rector de Salamanca durante el período de fray Luis en esa universidad: 1556 1557 y 1566-1567. Adviértase igualmente que, aunque hasta ahora no se haya dudado de la autenticidad de la dedicatoria general, Portocarrero no figura en ella como inquisidor.

La famosa y enigmática dedicatoria podría, por lo tanto, haber sido escrita no para la totalidad de las poesías, sino para un grupo de "obrecillas" compuestas - según el testimonio del autor - "entre las ocupaciones de mis estudios en mi mocedad, y casi en mi niñez" ${ }^{20}$. Esto resolvería algunos problemas de los

Fernández". Proceso de Martín Martínez de Cantalapiedra, edición y estudio de M. de la Pinta Llorente, Madrid, 1946. p. 3.

${ }^{20}$ Obras, p. 1425. 
muchos que presenta esta especie de prólogo. Tomado literalmente y referido a la totalidad de los poemas es o retórico, es decir, ficticio, o simplemente falso, pues sabemos que una buena parte de ellos, ciertamente la mejor, no pudo escribirse en la mocedad, ni en la casi niñez del poeta.

En cuanto a los tratados De los nombres de Cristo, también dedicados a Portocarrero, aquí ya (1583) el homenajeado lleva los títulos "del Consejo de Su Magestad y del de la Santa y General Inquisición". En cambio la composición de esta obra en la cárcel no es tan segura. Una vez más, se basa en el prólogo, que puede ser real o literario. "No cabe duda - escribe el P. Félix García - que, aunque es una obra de larga elaboración, se empezó a escribir en las cárceles del Santo Oficio. Del prefacio de los Nombres se deduce claramente" 21 . Lo que el P. Félix García llama prefacio es la dedicatoria a Portocarrero en la que, entre otras consideraciones, se encuentra ésta: "Mas ya que la vida pasada, ocupada y trabajosa, me fue estorbo para que no pusiese este mi deseo y juicio en ejecución, no me parece que debo perder la ocasión de este ocio, en que la injuria y mala voluntad de algunas personas me han puesto" 22 . El P. Félix anota: "Fray Luis escribe estas páginas en las cárceles de la Inquisición de Valladolid. De ahí el ocio, triste y forzoso por cierto de que habla" ${ }^{23}$.

Las dedicatorias literarias no se pueden tomar a la letra. Este ocio ha podido ser el de la cárcel o el de su celda o el de cualquier lugar en su imaginación. Valga otro tanto para las referencias que el editor hace a los pasajes de Job en los que parece aludirse a la cárcel. El único pasaje sin lugar a equívocos es el de la Explanación o exposición del salmo XXVI, dedicada al Inquisidor General Quiroga, de cuyo epílogo son las siguientes palabras: "Mas, dejando de hablar de materia ajena, hora es ya de que sólo trate y hable de mí, y de que convierta a mí mismo mi propia oración; que cuando esto escribo, soy oprimido de los mayores males, condenado a cárcel y hecho reo de infidelidad". Y en el siguiente párrafo: "Y pues hace ya catorce meses desde que mis enemigos empezaron a cantar victoria sobre mí, etc. " ${ }^{24}$ Estas

${ }^{21}$ Obras, p. 371.

${ }^{22}$ Obras, p. 390

${ }^{23}$ Obras, p. 390, nota 25.

${ }^{24}$ Obras, p. 1397. La explanatio fue escrita y publicada por fray Luis en latín (1580); la traducción es de F. Maldonado de Guevara, publicada originalmente en Cruz y Raya (septiembre 1934) y reproducida en esta edición de las Obras completas, pp. 1307-1310. 
líneas son lo suficientemente concretas, para tomarlas no literaria, sino literalmente.

Una vez establecido que ciertos poemas fundamentales han sido escritos en la cárcel o desde la experiencia de la cárcel, y establecido asimismo que las obras en prosa son posteriores a esa experiencia, a lo menos como productos acabados, no es difícil mantener que la totalidad de la obra de fray Luis debe ser referida a esa fuente. Esto no quiere decir, sin embargo, que haya que referir cada poema a una detallada circunstancia carcelaria, aunque en algún caso sea inevitable. Por ejemplo, la célebre décima, que alguien (no el autor) tituló "Al salir de la cárcel", y que fue colocada como epílogo apropiado de la primera parte de sus poesías originales, la "de las cosas que yo compuse mías":

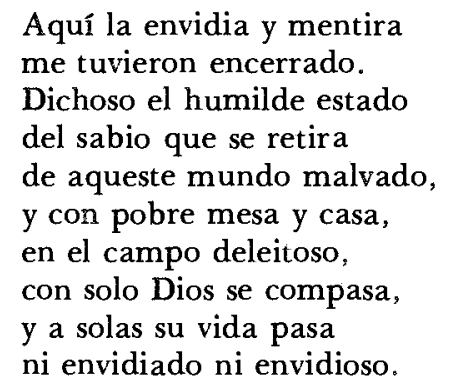

Su tema y estilo han dado pie no sólo a creer que se escribió en la cárcel de la Inquisición, sino en las paredes de la misma, para lo cual naturalmente no hay documentación alguna que lo pruebe. Coster simplemente se limita a fijar su fecha en diciembre de 1576, esto es, el mes en el que fray Luis sale de la cárcel. Su sentido, sin embargo, que es lo importante, no ofrece du$\mathrm{da}$, como tampoco la ofrecen las reacciones de sus enemigos de profesión, entre ellas la glosa de fray Domingo de Guzmán, dominico, y segundo hijo legítimo de Garcilaso de la Vega, contrincante de cátedra de fray Luis y parte principal en su segundo proceso. La desastrada glosa concluye:

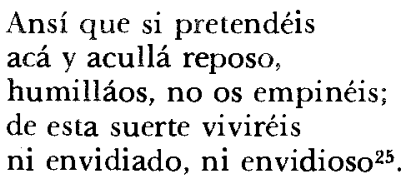

25 La composición completa puede verse en $B A E$, t. 37 , p. x. 
El poetastro daba en el clavo. La adversidad empinaba al poeta. La experiencia carcelaria de fray Luis es ante todo una reafirmación de sí mismo (no hay ruptura de la "ñudosa carrasca"), y esto se nota no sólo en la temática de sus obras castellanas, sino en su mismo tratamiento, que constituye, pretendido o no, un explícito desafío a la Inquisición. Al Cantar sigue Job traducido igualmente, no del latín, sino del hebreo, asunto que todavía fue problema para censores y editores en el siglo xvIII. No sabían si introducir la versión castellana de la Vulgata o traducir todo el comentario al latín.

De los nombres de Christo se abre con el mismo leitmotiv obsesivo: "De las calamidades de nuestros tiempos, que, como veremos son muchas y muy graves, una es, y no la menor de todas, muy ilustre señor, [Portocarrero] el haber venido los hombres a disposición que les sea ponzoñosa lo que les solía ser medicina y remedio: que es también claro indicio de que se les acerca su fin, y de que el mundo está vecino a la muerte, pues la haya en la vida".

"Notoria cosa es que las Escrituras..." ${ }^{26}$ Fray Luis, dirigiéndose a un miembro del Consejo Supremo de la Inquisición, más tarde Inquisidor General, mantiene tozuda, casi heroicamente, que las Escrituras tienen un fin universal y que, por lo tanto, deben ser comunes a todos, y a cada uno en su lengua. "Y porque las escribió para este fin, que es universal, también es manifiesto que pretendió que el uso de ellas fuese comün a todos, y así, cuanto es de su parte, lo hizo: porque las compuso con palabras llanísimas y en lengua que era vulgar a aquellos a quien las dio primero" ${ }^{27}$. La cárcel no le ha hecho cambiar un ápice, antes al contrario, lo ha acendrado.

Temáticamente, la continuidad de fray Luis, reafirmada en la cárcel, es evidente. Toda su obra no es más que un comentario en pleno castellano a la Escritura "hebrea" con intención de que llegue a esa "turba multa", que el Maestro Sancho le aconsejaba no contentar y que enfurecía a Melchor Cano. Tampoco hay cambio, a no ser en sentido sublimado, en el tratamiento de los temas. Otra vez el acendramiento del desmoche, que en este caso es de consecuencias substanciales, aunque no radicalmente diversas. Como no hay ruptura entre el Cantar y Job, tampoco la hay entre De la vida retirada, anterior a la cárcel, y De la vida del cielo, posterior a ella. Seguimos en el campo de la égloga, sólo que elevada al espacio celeste, característico de la mística o

\footnotetext{
${ }^{26}$ Obras, p. 385.
}

${ }^{27}$ Obras, p. 385 . 
misticismo de la época. Recordemos que fray Luis no sólo es el primer editor de Santa Teresa (a petición de la Inquisición), sino su biógrafo. Otro tanto ocurre con las obras de San Juan de la Cruz, cuyo primer editor y apologeta es fray Basilio Ponce de León, sobrino de fray Luis.

Una última palabra para terminar y enlazar con el segundo autor procesado de este artículo. ¿Tiene algo que ver toda esta inmensa y sutil trama con la condición de conversos en que se encuadra socialmente la familia de fray Luis? Realmente muy poco. Documentalmente no hay más que el incidente del traslado a Belmonte (Cuenca) su ciudad natal, de los sambenitos de su bisabuela y de la hermana de ésta, que habían sido reconciliadas en un auto de fe en Cuenca, en 1512. Las infamantes prendas, expuestas en la catedral de Cuenca, desde entonces, fueron mandadas trasladar a Belmonte en 1529, cuando fray Luis tenía dos años. La familia se opuso, y el pleito no se resolvió hasta 1548, y en favor de la Inquisición. La familia quedaba con ello infama$\mathrm{da}$, aunque no inhabilitada. Para entonces fray Luis llevaba ya siete años en Salamanca. En la misma fecha y quizás por el mismo motivo - según Bell - su padre se había trasladado a Granada como juez. De creer la declaración que fray Luis hace de su genealogía ante los inquisidores, él había abandonado Belmonte a la edad "de cinco o seis años, y de esta edad le llevaron a Madrid, donde estaba la corte, y en ella se crió en casa de su padre que era entonces abogado de corte, y en esta villa [Valladolid] cuando la corte se pasó a ella, hasta que tuvo edad de catorce años" 28 .

La infancia de fray Luis y su mocedad se han desarrollado, por lo tanto, fuera de la infamada familia de Cuenca, con la que mantiene buenas relaciones toda su vida. Pero además, en el mismo pasaje, fray Luis niega de forma terminante que en su familia haya converso alguno: "Y no se hallará en memoria de hombres ni de escrituras ciertas que nombrada y señaladamente alguno de todos mis antecesores se haya convertido a la fe de nuevo". ¿Eran esas señoras de los sambenitos relaciones de segundas nupcias de su bisabuelo Lope de León? Posiblemente. Pero aunque éste no fuese el caso, la obra de fray Luis tiene perfecta explicación sin él. Converso o no, se trata de un humanista de la escuela de Cipriano de Huerga, empapado de Garcilaso, que entra en conflicto con la Inquisición, gracias a sus colegas universitarios formados en otra tradición y representando

${ }^{28}$ CODOIN, t. 10 , p. 386 . 
otros intereses indudablemente arcaicos. Lo demás son pajas de la profesión y del tiempo.

\section{Antonio EnRÍQUez Gómez}

Gracias a los minuciosos trabajos de Israel Salvator Révah, y de su continuador y discípulo, Charles Amiel, la vida y la obra de Antonio Enríquez Gómez empiezan a salir del enredo en que las envolvió, por necesidad y afición, su propio autor. Además de tratarse de un auténtico criptojudío, activista político, por añadidura, era empedernido culterano "y contagiado hasta los tuétanos de los vicios de la época, y de otros propios y pecualiares suyos" 29 .

En su edición de la segunda parte de la Política angélica, de Enríquez, formidable alegato contra la Inquisición española, Révah, con su acostumbrada erudición, recoge y corrige cuanto hasta ahora se sabía sobre el autor y su obra. Charles Amiel, en menor escala, aunque con mayor aliento, lleva a cabo una labor semejante al editar El Siglo Pitagórico. En esta cuidada edición se nos promete un Antonio Enríquez Gómez (1600-1663) o la disimulación marrana, en el que "el hombre, la obra, el medio, serán presentados en detalle, par le menu"so.

En espera de publicar la obra definitiva ${ }^{31}$,ni Révah, ni Amiel revelan, en sus respectivos trabajos, las fuentes sobre que se ba-

${ }^{29}$ Heterodoxos, t. 4, p. 315. En este caso, como en tantos otros, el juicio de Menéndez Pelayo, a pesar de su tono y excesos verbales, es extraordinariamente exacto en su conjunto y de una gran percepción de detalles al tratar del valor literario de las obras individuales de Enríquez.

${ }^{30}$ I. S. RÉ VAH, "Un pamphlet contre l'Inquisition d'Antonio Enríquez Gómez: la seconde partie de la Política Angélica (Rouen, 1647)", Revue des Études Juives, 121/122 (1962), 81-168, en adelante, Un pamphlet. Antonio Enríquez Gómez, El Siglo Pitagórico y Vida de Don Gregorio Guadaña, éd. critique avec introduction et notes par Charles Amiel, Paris, 1977. (Aprovecho esta oportunidad para agradecer al profesor Amiel su generosidad en informarme sobre el paradero de los papeles de su lamentado colega y maestro Révah, así como sobre su propia obra, que tuvo la gentileza de ofrecerme dedicada).

${ }^{31}$ Para otros detalles, véase mi crónica del ler. Symposium Internacional de Cuenca (España), "Estado actual de estudios sobre la Inquisición", $A \mathrm{r} b$, 396 (1978), 85-96. - En el Archivo Histórico Nacional de Madrid, sección de Inquisición, se conservan tres legajos referentes a Antonio Enríquez Gómez: dos autos de secuestros, uno del tribunal de Sevilla (1660) y otro, del tribunal de Corte (1677) y las actas del litigio "contra Miguel Fernández Fonseca, por 131 libras de seda". Año 1624. Legajo 3.658, núm. 16. 
san, ni siquiera cuando citan directamente. No creo, sin embargo, que el proceso de Enríquez se haya encontrado todavía, aunque posiblemente estamos cerca de él, si las noticias del destino actual del archivo de la Inquisición de Sevilla se confirmasen .

Lo que hoy sabemos, gracias sobre todo a las investigaciones de Révah, a quien sigo en esta materia, es que Antonio Enríquez Gómez perteneció a una familia de conversos en el más estricto sentido de la abusada denominación. Tanto él como sus padres, abuelos, tíos y otros parientes han tenido múltiples conflictos con la Inquisición, siempre por el mismo motivo: su judaísmo encubierto, es decir, su condición de marranos o anusin ${ }^{32}$.

Enríquez nació en Cuenca, no en Portugal, ni en Segovia, hacia 1600 , de padre marrano y madre cristiana vieja. Su padre fue condenado en Cuenca en 1624, y, tal vez por estas fechas, se traslada a Francia donde se casa en segundas nupcias con cristiana nueva. Como en el caso de fray Luis, el hacha inquisitorial no los arranca de su condición, sino que los confirma en ella. Sólo que fray Luis era cristiano y humanista, y Enríquez judío y mercader. Su abuelo paterno (que no era portugués, sino de Quintanar de la Orden, en La Mancha) había muerto en las cárceles de las Inquisición de Toledo, de muerte natural, en 1588, en circunstancias muy semejantes a las que sufre Enrí quez, en 1663.

Nuestro autor pasa algo más de la mitad de su vida en España, entre Cuenca, Sevilla y Madrid. Cuenca es su ciudad natal, y en ella da comienzo a su carrera literaria. En Sevilla estuvo al servicio o en el negocio de su tío paterno, Antonio Enríquez de Mora. De aquí que, cuando quiera incorporarse a España, después de trece años de exilio en Francia, vuelva con nombre fingido, no a Cuenca o Madrid, sino a Sevilla. En 1618 se había casado con Isabel Basurto, cristiana vieja de Zafra, y en 1624 le encontramos instalado en Madrid. El hermano de Isabel (según Amiel, su padre) fue comisario de la Inquisición en Aravaca y las Rozas.

Diez años después, en 1634, en una investigación inquisitorial se le describe como "mercader de lonja [es decir, mayorista] de cosas de Francia, que bive en la entrada de la calle de San Luiz, por la puerta del Sol, en casas de Diego Rodríguez Solís" "3s. Característicamente, el primer pleito de Enríquez con la Inquisi-

${ }^{32}$ En la inmensa literatura sobre el tema, es poco citada la extraordinaria obra del profesor BENZION NETANYAHU, The marranos of Spain, New York, 1966 [reimpr. 1973].

${ }^{39}$ RÉVAH, Un pamphlet, p. 83 
ción es por rescatar los bienes de su madre, que la Inquisición de Cuenca les había confiscado. Durante toda esta época de su estancia en Madrid (1624-1635), divide el tiempo entre el teatro y el comercio, haciendo frecuentes viajes a Nantes, donde se ha instalado su padre, y a Burdeos, donde se encuentra su tío Antonio Enríquez de Mora, que había escapado por los pelos de la Inquisición de Sevilla.

Al salir de España, en 1635 o 1636, Enríquez es probablemente autor dramático bien conocido en la Corte. De ello dan testimonio, Manuel Fernandes Vilareal, Cónsul de Portugal en París, que prologa Academias morales de las musas, en 1642, y el propio Enríquez en Sansón Nazareno, en 1656. El hecho de que su soneto "A la muerte feliz del Doctor Frey Lope de Vega Carpio", fuese publicado en la Fama póstuma, de Montalbán, en 1635 , es prueba de ello.

Los motivos de su salida de España, como los de su vuelta clandestina, no están nada claros. A su condición de anusim, se añaden pleitos financieros, quiebras y deudas simplemente sin pagar, como la de los paños de Segovia, además de sus intrigas políticas. Su "peregrinación fue - según su propio testimonio algo enrevesado - si no voluntaria, forçosa: y si no forçosa, ocasionada por algunos que, ynficionando la República, recíprocamente falsos, venden por antídoto el beneno a los que militan debaxo del solio..." El hecho es que Antonio Enríquez está complicado en la restauración portuguesa, como lo prueba su Triunfo Lusitano, 1641. De aquí, y del Político Christianisimo, de M. Fernandes Vilareal, viene la leyenda de su origen portugués. Además, las comunidades de judíos hispano-portugueses eran simplemente conocidas como "nación portuguesa".

En 1643 (siempre siguiendo a Révah) pasa de Burdeos a Rouen. La tragedia religioso-racial de la familia se complica en cada paso. A Rouen le siguen su mujer, su hija Leonor, y un hijo, Diego Enríquez Basurto, tan aficionado a las letras como su padre, pero bastante más desgraciado en ellas y en su destino errante. El cuadro que del autor de El triumpho de la virtud y paciencia de Job (Rouen, 1649) nos hace la Carta satírica, de Miguel de Barrios, es verdaderamente patéticos ${ }^{\text {s4 }}$

Otra hija de Enríquez, Catalina, se queda en Madrid donde casa con un familiar de la Inquisición, a quien Enríquez convierte característicamente en su "agente comercial en España". Du-

\footnotetext{
34 “Diego Enríquez Basurto", apéndice II, de la ed. de El siglo pitagórico,
} 
rante el primer año en Rouen, 1644, publica La culpa del primer peregrino, y El Siglo Pitagórico. Según Révah, en ésta como en otras obras suyas, el tema del malsin, aparece como una ver. dadera obsesión. Révah no nota, sin embargo, que el familiar es la versión cristiana del malsin hebreo.

Del año siguiente, 1645, es su segunda obra política, Luis $d a$ do de Dios, dedicada a Luis XIV. Los ataques a la Inquisición, en forma más o menos abierta, anuncian ya la Política angélica: "¿Qué fin puede aguardar un Reyno que premia malsines, alimenta cuadrilla de ladrones (como dice San Agustín), destierra vasallos, deshonra linajes, ensalza libelos, multiplica ministros, destruye el comercio, ama adbitrios [sic], roba los pueblos, confisca bienes, hace juiçios secretos, no oye las partes, calla los testigos, vende noblezas, condena nobles, alienta gabelas y arruina el derecho de las gentes?" 55 . El tema vuelve a aparecer con toda su fuerza en la Política Angélica, quizás el único tratado antiinquisitorial de toda la literatura española, y una de las dos obras prohibidas por la Inquisición. La otra fue La Torre de Babilonia, donde se encuentra su Fernán Méndez Pinto, comedia famosa en dos partes ${ }^{36}$.

Tanto Amiel, como Constance H. Rose, señalan el tema del exilio como esencial a esta obra. Exilio e Inquisición son ciertamente las coordenadas de la vida de Antonio Enríquez y quizás puedan serlo para explicar la totalidad de su obra o lo esencial de ella. Rose, sin embargo, parece exagerar al decir que este ser $e x$ illis es "el único dato inescapable de su existencia". Tal vez sin notarlo se ha dejado llevar del soniquete de la frase de María Rosa Lida sobre Rojas: "este dato [que era converso], prácticamente el único externo que se conoce de Fernando de Rojas".

En cualquier caso, desprovisto de su carácter de fatalidad y reducido a proporciones, el exilio es la respuesta de Enríquez al reto que le presenta la Inquisición; un exilio paradójicamente autoinfligido y necesario a la vez, como él escribió de Fernán Méndez Pinto.En el caso de esta obra es posible incluso que haya

de Amiel. La última o penúltima seguidilla de la Carta crítica la fecha en Amberes, 28 de marzo de 1664.

${ }^{85}$ Luis dado de Dios. . . Paris, René Baudry, 1645, pp. 118-119. RÉVAH, Un pamphlet, pp. 85-86.

${ }^{36}$ Charles Amiel prepara una edición crítica de La Torre de Babilonia, sin la comedia, que han editado Francisco M. Rogers, Louise G. Cohen, y Constance H. Rose con sendos estudios, en Harvard University Press, 1974. El estudio de Rose, revisado y ampliado, aparece en $R F, 85$ (1973), 63-77, bajo el título "Antonio Enríquez Gómez and the literature of exile". 
que tomar a la letra los paralelismos entre la vida del autor y su protagonista, ambos judíos peninsulares errantes, que llegan a obtener puestos de poder importantes en un país extranjero. Desde luego, la perigrinación de ambos no fue la de "la persona que por devoción o por voto va a visitar un santuario". Ni este peregrino es "el que sale de su tierra en romería a visitar alguna casa santa o lugar santo" (Covarrubias).

Como bien nota Rose, la peregrinación está vinculada a la búsqueda de una honra que no puede conseguir en su propio país por razones raciales o de limpieza de sangre. Al citar a San Jerónimo pidiendo que las honras, es decir, los títulos del poder y la nobleza "no se han de dar por sangre, sino por virtud", Enríquez está exigiendo para su grupo étnico, el de los judeoconversos hispanoportugueses, una libertad que les había sido negada desde la sentencia estatuto de Toledo de 1449, y la vez un "puerto seguro", que fray Luis le aconsejaría buscar sólo en la gloria del cielo o en el recóndito hondón del alma donde aquélla se refleja.

La fortuna, implacable solamente para los que creen en ella, llevó a Enríquez, en su eterno peregrinar, a Sevilla, hacia 1649 o 1650, después de pasar de incógnito por Pastrana y Madrid, y de haber sido aconsejado por el comisario de Aravaca que siguiese camino hacia el sur. Antonio Enríquez permaneció en Sevilla, bajo el seudónimo de Don Fernando de Zárate, hasta el año de su muerte en 1663. Su primo y compañero, Enríquez de Mora, hijo de aquel tío que le acogió en Sevilla, siguió hasta América, donde también cayó en las redes de la inquisición de Lima. Este último dato complica la existencia de Enríquez y la labor de la crítica. Tanto Rose como Amiel, ambos basados en el testimonio de Révah, que no revela sus fuentes, afirman que "hacia 1649, Antonio Enríquez Gómez volvió a Sevilla y vivió en Sevilla bajo el nombre de Don Fernando de Zárate; teniendo así el privilegio de verse quemar en efigie en el espectacular auto del mes de abril de 1660"'s7.

Antiguamente corría una historia diferente, después desmentida, y desde luego en contradicción con la arriba referida. "Don Adolfo de Castro - escribe La Barrera - hablando de este asunto y de la quema figurada de Enríquez, refiere, sin expresar su origen, la siguiente anécdota: «Es fama, que hallándose Enríquez en Amsterdam, topó un día con un español, su amigo, recién llegado a aquellas tierras, y como éste le dijese: $-{ }_{j}$ Oh señor

${ }^{37}$ REVAH, Un pamphlet, p. 112. 
Enríquez! yo vi quemar vuestra estatua en Sevilla. Respondió prestamente con gran risa: - Allá me las den todas»" ${ }^{88}$.

En espera de que Amiel nos revele la fuente de ésta y de otras particularidades de las relaciones de Enríquez con la Inquisición, aceptemos que fue así; que Enríquez tuvo dos procesos, por lo menos, uno en ausencia y otro en persona; y que en el primero en 1660 es "condenado en efigie", mientras en el segundo se le "reconcilia [también] en efigie", en el auto de fe celebrado en San Pablo de Sevilla, el 14 de junio de 1665.

La historia continúa después de muerto. Basada en las declaraciones de sus primos en Lima, la Suprema, por decisiones del 7 de septiembre de 1665 y 7 de enero de 1668, ordena que se abra la causa de "Antonio Henríquez Gómez, alias Don Fernando de Zárate, reconciliado en estatua en Inquisición de Sevilla". Como en tantas otras ocasiones, el juez de bienes confiscados andaba tras los del difunto en 1677-1678 con "pocas esperanzas de utilidad, por lo recargado de este negocio" 39 .

El problema del alias sigue sin resolver. A pesar de los esfuerzos de La Barrera, hoy no sabemos qué comedias de Enríquez salieron bajo el nombre de Zárate, ni si este nombre corresponde a la vez a un autor real y al seudónimo de Enríquez. La única comedia prohibida por la Inquisición bajo el seudónimo es $E l c a$ pellán de la Virgen, que La Barrera asigna a Lope: "la publicó en su Parte diez y ocho; no consta otra de este título en los Catálogos". Más adelante, basado en la respuesta de Mesonero a don Adolfo de Castro, dice: "El capellán de la Virgen, San Idelfonso, fue escrita por Lope, y por él mismo publicada en la Parte diez y siete de las suyas, año de 1623. Cierto es que puede haber otra pieza posterior del mismo título, o refundición de la compuesta por Lope, si bien sólo hallamos citada ésta en los Catálogos; pero en tal caso, ¿por qué el Santo Oficio no hizo la conveniente distinción entre ambos dramas?" "40. Esperemos que Amiel nos aclare también estos problemas, pues las otras atribuciones a Zárate hacen de Enríquez un escritor de vidas de santos, cosa difícil de compaginar con el anusim autor de la Política angélica.

De la primera parte de la Política angélica se conservan tres ejemplares todos en Lisboa. De la "segunda parte", que es la dedicada a la Inquisición, sólo hay uno, descubierto por Révah en

${ }^{38}$ ADOLFo DE CASTRo, Historia de los judíos en España, 1847; CAYETANO ALBERTO DE LA BARRERA Y LEIRADO, Catálogo bibliográfico del teatro antiguo español, Madrid, Rivadeneyra, 1860.

${ }^{39}$ RÉVAH, Un pamphlet, p. 114 (subrayado añadido).

${ }^{40}$ Catálogo bibliográfico, pp. 139-140. 
la Biblioteca de Mazarino, en París. Ningún lugar más adecuado para este ejemplar único.

En comparación con la primera parte, donde los temas inquisitoriales empiezan a develarse cautamente, la segunda es un alarde de crítica y utopía, desde el mismo frontis: Política / Angélica /sobre el govierno, que se deve / tener con los Reduzidos a la Fe Catholica, y con los / que se apartaron della/. Diálogo 3. y 4./ dedicada, a todos los Príncipes / Christianos, Columnas de la Militante Iglesia de Roma./ por / Antonio Henríquez Gómez, / Cavallero de la Orden de su Magestad Christianissima, / y su Consejero y Majordomo ordinario./ (viñeta) En Roan / En la imprenta de Laurens Maurry. Año 1647 / Con aprobación/.

El grandioso objetivo, poco antes concebido por Olivares y satirizado por Quevedo, era la vuelta de los judíos y judeoconversos como medio de remediar la catástrofe financiera de la monarquía española. Pero esto equivalía a destruir la Inquisición peninsular, y de aquí que inmediatamente los inquisidores y la embajada de Portugal se den por enterados de la amenaza y negocien con Francia, vía diplomática, la destrucción de los ejemplares impresos y la entrega del manuscrito. El proceso inquisitorial contra su amigo Manuel Fernandes Vilareal, que muere en la hoguera, lleva entre sus cargos tener este libro, "o qual livro tinha cousas muito infames contra o Santo Officio" ${ }^{4 !}$.

De hecho, la razón de que exista una segunda parte de la Política angélica (Diálogo [sic] 3 y 4), dedicada a la Inquisición fue precisamente debida a la intervención del Cónsul, y de su embajador, con el Rey y el Parlamento de Rouen, los cuales suspendieron la obra en la forma que había sido originalmente concebida. Al arrancar de ella la parte más escandalosa, ésta se publica después por separado como "segunda parte". "El panfleto que estudiamos - nos dice Révah - es un ejercicio literario e intelectual típicamente marrano: un judaizante que trata de situarse en la posición de un católico y busca los argumentos que este último podría oponer a los métodos inquisitoriales y al racismo religioso en vigor en esa época en España y Portugal" 42.

La obra tiene antecedentes doctrinales como la Alegación, "impresa, pero no publicada", de Martín de Zellorigo, 1619, que Enríquez ha podido conocer. Otro contexto contemporáneo son los escritos del P. Antonio Vieira, en favor de los cristianos nuevos en 1643, 1646 y 1647, fecha esta última de la Política an-

${ }^{41}$ Proceso de M. Fernandes Vilareal, Archivo Nacional de la Torre do Tombo (Lisboa), proceso núm. 7.791, fol. 58 (RẺVAH, Un pamphlet, p. 95).

${ }^{42}$ RÉVAH, Un pamphlet, p. 101. 
gélica. Enríquez y el célebre jesuita portugués se han conocido probablemente en Rouen. Pero sus puntos de vista no están armonizados. Ambos autores insisten en la ilegalidad de la confiscación de bienes. El hecho se explica, en cuanto a los jesuitas, por la necesidad de obtener de los nuevos cristianos el capital necesario para la formación de la Compañía General de Comercio del Brasil. Enríquez es bastante más utópico y metafísico.

Tal vez pueda extrañar que la segunda parte de la Política angélica no sea sólo un "elocuente y vehemente" ataque a la Inquisición, sino un plan de reforma de la misma. El molde reformista había sido siempre, desde los tiempos de Felipe el Hermoso, la única fórmula posible de oposición al Santo Oficio, y lo va a seguir siendo hasta las Cortes de Cádiz. En realidad, lo que se trataba era de abolirlo. La sinceridad de Enríquez en este aspecto es más que discutible. En el elogio va envuelta la daga. De todas las formas, se explaya sobre detalles ideales aconsejando que los inquisidores sean carmelitas y jesuitas, en vez de franciscanos y dominicos, y que la ley evangélica se tome como guía, aboliendo, de paso, las prácticas que más le afectan: la confiscación, la vergüenza pública y la inhabilidad de los descendientes de los condenados.

Révah cree que el famoso panfleto no tuvo repercusión alguna ni en la transformación de la Inquisición peninsular (lo cual era de esperar), ni en el destino último del autor. Esto ya no es tan seguro. En un testimonio que él mismo cita, aunque como de costumbre ocultando la fuente, su hermano de padre, Esteban Enríquez, declara que Antonio pensaba exiliarse de nuevo, esta vez a Nápoles, tan pronto llegasen las galeras de América. ¿Razón? Temía que se descubriese cualquier día que él era el autor de la Política angélica y que esto fuese suficiente delito para su condena. Tenía razón. Pero en el mismo testimonio se nos dice que Enríquez había tenido la audacia o, mejor dicho, la angélica candidez política, de enviar ejemplares de su libro no sólo a los magistrados, sino a los inquisidores.

Aquí procedería terminar haciendo una comparación detallada de estos dos conversos conquenses, si los hechos no hablasen por sí mismos. Hay, sin embargo, quien cree que los hechos no tienen voz propia. Pero para éstos tampoco valdría nada el argumento. Dejemos, pues, el hilo de los conversos y su complicada crítica aquí.

ANTONIO MÁRQUEZ 